\title{
EDITORIAL
}

Holm Altenbach • Victor A. Eremeyev (D)

\section{Generalized continua with applications: Euromech Solid Mechanics Conference 2018}

Published online: 1 October 2019

(C) Springer-Verlag GmbH Germany, part of Springer Nature 2019

\begin{abstract}
Motivating by two minisymposia on generalized models of continua organized within the Euromech Solid Mechanics Conference, Bologna, Italy 2018, we introduce the corresponding special issue based on these events.
\end{abstract}

Keywords Generalized continua - Cohesion-adhesion Interactions · Thin structures · Euromech Solid Mechanics Conference

\section{Introduction}

Recently, the interest to generalized models of continua and structures grows with respect to possibility of the proper description of materials and structures with complex inner structure such as metamaterials. It is worth to note the generalized models can also extend the further application of continuum and structural mechanics to material modelling at the nanoscale or to take into account complex physical coupling with other fields.

As a result of the mentioned, one can see the significant increase in publications in the field and conference lectures. It is worth to mention the celebration of 100th years of the book by Cosserat brothers; see [17]. Last decade, a lot of publications appears in the field; see, e.g., collections [1-7,11,17], monographs [8,14-16], and reports on several events $[12,18,19]$. Note that nowadays the generalized models of continua are even included as a part in textbooks on continuum mechanics; see, e.g., [9, 10,13].

As a proof of the interest to generalized media, one can consider recent 10th European Solid Mechanics Conference which took place from July 2 to 6, 2018, in the Bologna, Italy. The conference was organized by the Universities of Bologna and Trento, under the auspices of EuroMech, with Professors Davide Bigoni (University of Trento) and Francesco Ubertini (University of Bologna) as chairmen. Within the conference, there were two minisymposia called "Mechanics of Generalized Continua with-Mechanics of Cohesion-adhesion

H. Altenbach

Lehrstuhl für Technische Mechanik, Institut für Mechanik, Fakultät für Maschinenbau, Otto-von-Guericke-Universität Magdeburg, 39106 Magdeburg, Germany

E-mail: holm.altenbach@ovgu.de

V. A. Eremeyev ( $\varangle)$

Faculty of Civil and Environmental Engineering, Gdańsk University of Technology, ul. Gabriela Narutowicza 11/12, 80-233 Gdańsk, Poland

E-mail: eremeyev.victor@gmail.com

V. A. Eremeyev

Research Institute for Mechanics, National Research Lobachevsky State University of Nizhni Novgorod, Nizhni Novgorod, Russia 
Interactions and their Applications to Size-dependent Thin Structures" organized by Holm Altenbach (Ottovon-Guericke Universität Magdeburg, Germany), Sergey Lurie (Russian Academy of Sciences, Moscow) and Nikita Morozov (Saint Petersburg State University and Russian Academy of Sciences, Russia), and "Mechanics of Generalized Continua with Applications to Microstructured Materials" organized by Victor Eremeyev (Gdańsk University of Technology, Poland), Patrizio Neff (Universität Duisburg-Essen, Germany) and Panos Gourgiotis (Durham University, UK).

During these minisymposia, the main attention was paid to the following topics:

- micropolar and micromorphic continua;

- strain gradient media;

- surface elasticity;

- coupled models and phase transitions;

- discrete models of continua;

- peridynamics;

together with various applications to mechanics of composites, thin structures and metamaterials, theory of adhesion and wave dynamics.

The special issue "Generalized media with applications" collects selected papers presented during these minisymposia and papers of known specialists in the field.

\section{References}

1. Altenbach, H., Belyaev, A., Eremeyev, V.A., Krivtsov, A., Porubov, A.V. (eds.): Dynamical Processes in Generalized Continua and Structures, Advanced Structured Materials, vol. 103. Springer, Cham (2019)

2. Altenbach, H., Eremeyev, V.A. (eds.): Generalized Continua: From the Theory to Engineering Applications. CISM Courses and Lectures. Springer, Wien (2013)

3. Altenbach, H., Forest, S. (eds.): Generalized Continua as Models for Classical and Advanced Materials, Advanced Structured Materials, vol. 42. Springer, Cham (2016)

4. Altenbach, H., Forest, S., Krivtsov, A. (eds.): Generalized Continua as Models for Materials: With Multi-scale Effects or Under Multi-field Actions, Advanced Structured Materials, vol. 22. Springer, Berlin (2013)

5. Altenbach, H., Maugin, G.A., Erofeev, V. (eds.): Mechanics of Generalized Continua, Advanced Structured Materials, vol. 7. Springer, Berlin (2011)

6. Altenbach, H., Pouget, J., Rousseau, M., Collet, B., Michelitsch, T. (eds.): Generalized Models and Non-classical Approaches in Complex Materials 1, Advanced Structured Materials, vol. 89. Springer, Cham (2018)

7. Altenbach, H., Pouget, J., Rousseau, M., Collet, B., Michelitsch, T. (eds.): Generalized Models and Non-classical Approaches in Complex Materials 2, Advanced Structured Materials, vol. 90. Springer, Cham (2018)

8. Bertram, A.: Compendium on Gradient Materials Including Solids and Fluids. TU Berlin, Berlin (2019)

9. Besson, J., Cailletaud, G., Chaboche, J.L., Forest, S., Blétry, M.: Non-linear Mechanics of Materials, Solid Mechanics and Its Applications, vol. 167. Springer, Dordrecht (2010)

10. Clayton, J.D.: Nonlinear Mechanics of Crystals, Solid Mechanics and Its Applications, vol. 177. Springer, Dordrecht (2011)

11. dell'Isola, F., Eremeyev, V.A., Porubov, A.V. (eds.): Advances in Mechanics of Microstructured Media and Structures, Advanced Structured Materials, vol. 87. Springer, Cham (2018)

12. dell'Isola, F., Forest, S.: Second Gradient and Generalized Continua. A Workshop Held on 12-16 March 2012 in Cisterna di Latina. ZAMM 94(5), 367-372 (2014)

13. Eremeyev, V.A., Cloud, M.J., Lebedev, L.P.: Applications of Tensor Analysis in Continuum Mechanics. World Scientific, New Jersey (2018)

14. Eremeyev, V.A., Lebedev, L.P., Altenbach, H.: Foundations of Micropolar Mechanics. Springer-Briefs in Applied Sciences and Technologies. Springer, Heidelberg (2013)

15. Maugin, G.A.: Continuum Mechanics Through the Twentieth Century: A Concise Historical Perspective. Springer, Dordrecht (2013)

16. Maugin, G.A.: Non-classical Continuum Mechanics: A Dictionary, Advanced Structured Materials, vol. 51. Springer, Singapore (2017)

17. Maugin, G.A., Metrikine, A.V. (eds.): Mechanics of Generalized Continua: One Hundred Years After the Cosserats. Springer, New York (2010)

18. Misra, A., Placidi, L., Scerrato, D.: A review of presentations and discussions of the workshop Computational mechanics of generalized continua and applications to materials with microstructure that was held in Catania 29-31 October 2015. Math. Mech. Solids 22(9), 1891-1904 (2017)

19. Placidi, L., Giorgio, I., Della Corte, A., Scerrato, D.: Euromech 563 Cisterna di Latina 17-21 March 2014 generalized continua and their applications to the design of composites and metamaterials: a review of presentations and discussions. Math. Mech. Solids 22(2), 144-157 (2017)

Publisher's Note Springer Nature remains neutral with regard to jurisdictional claims in published maps and institutional affiliations. 